\title{
Studies on the breeding swarms of Anopheles gambiae complex in malaria control perspective
}

\author{
Benoît S Assogba ${ }^{1,2^{*}}$, Luc S Djogbenou ${ }^{1,2}$, Roch K Dabiré ${ }^{3}$, Abdoulaye Diabaté ${ }^{3}$, Thierry Baldet ${ }^{2}$ \\ From Parasite to Prevention: Advances in the understanding of malaria \\ Edinburgh, UK. 20-22 October 2010
}

\section{Background}

To reduce malaria transmission through vector control, alternative measures are necessary as transgenic mosquitoes are resistant to Plasmodium [1] and sterile insect technique (SIT) [2]. Both approaches require a fine understanding of the biology of reproduction of Anopheles gambiae complex. This study aims to characterize the swarm structure and several environmental parameters associated with distribution of breeding swams and sites in the south of Benin.

\section{Methods}

After the survey in field, molecular analyses were done and productive breeding sites, breeding swarms and human habitations positions were integrated into a map using a geographic information system.

\section{Results}

The molecular identification of 510 males collected from 17 swarms and 680 females from larvae of An. gambiae s.l. has allowed the description of breeding swarms and sites characteristic of two species: An. gambiae $\mathrm{M}$ and An. melas (Figures 1,2,3) as well as their distribution (Figures 4,5). These results indicate that the swarming and mating system involved mainly mosquitoes of the same species, suggesting the existence of specific factors related to the mating system of each species.

\section{Conclusion}

Further studies on the swarming and mating system of An. gambiae s.l. need to be conducted to produce a predictive model of swarm distribution to aid malaria eradication strategies based on the use of generalized method of moments and SIT.

${ }^{1}$ IRSP/UAC, 01BP918Cotonou, Bénin

Full list of author information is available at the end of the article

\section{Acknowledgements}

We are very grateful to MIM/TDR/WHO for financial support. MIM grant ID: A80690.

\section{Author details}

${ }^{1}$ IRSP/UAC, 01BP918Cotonou, Bénin. ${ }^{2}$ CREC/IRD/UR016, 06BP2604Cotonou, Benin. ${ }^{3}$ Centre Muraz/IRSS BP 390 Bobo-Dioulasso, Burkina-Faso.

Published: 20 October 2010

\section{References}

1. WHO: Report on planning meeting 1. 2010, Geneva, Switzerland, 4-6 May 2009.

2. Alphey L, Benedict M, Bellini R, Clark GG, Dame DA, Service MW, Dobson SL: Sterile-insect methods for control of mosquito-borne diseases: an analysis. Vector Borne Zoonotic Dis 2010, 10:295-31.

doi:10.1186/1475-2875-9-S2-O1

Cite this article as: Assogba et al:: Studies on the breeding swarms of Anopheles gambiae complex in malaria control perspective. Malaria Journal 2010 9(Suppl 2):01.
Submit your next manuscript to BioMed Central and take full advantage of:

- Convenient online submission

- Thorough peer review

- No space constraints or color figure charges

- Immediate publication on acceptance

- Inclusion in PubMed, CAS, Scopus and Google Scholar

- Research which is freely available for redistribution

Submit your manuscript at www.biomedcentral.com/submit
() Biomed Central

\section{() Biomed Central}

(c) 2010 Assogba et al; licensee BioMed Central Ltd. This is an open access article distributed under the terms of the Creative Commons Attribution License (http://creativecommons.org/licenses/by/2.0), which permits unrestricted use, distribution, and reproduction in any medium, provided the original work is properly cited. 


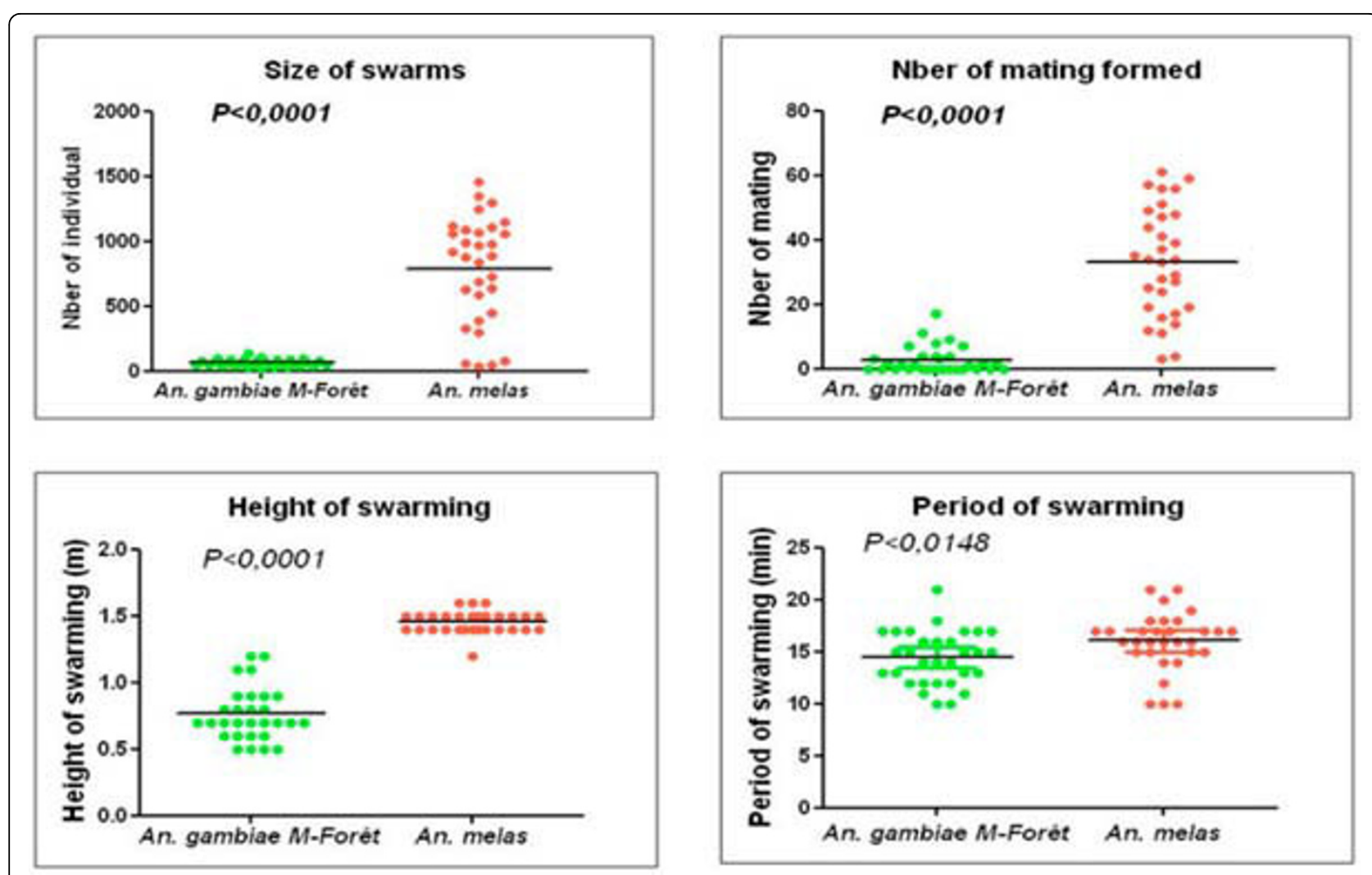

Figure 1 Comparison of swarm size, swarming period, height and number of mating couples observed between the swarms of An. gambiae s.s. $M$ and An. melas.
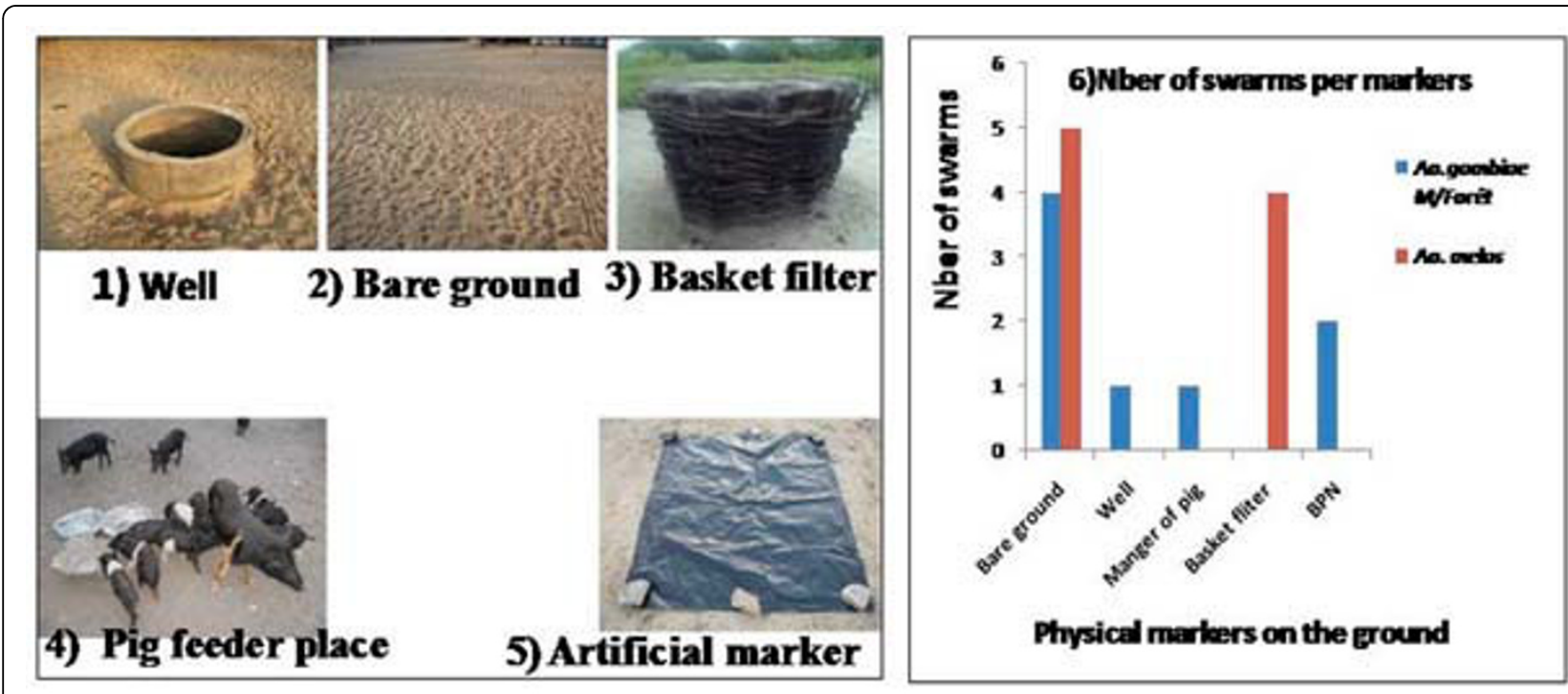

Figure 2 Physical markers of An.gambiae $\mathrm{M}$ and An. melas swarm sites. 

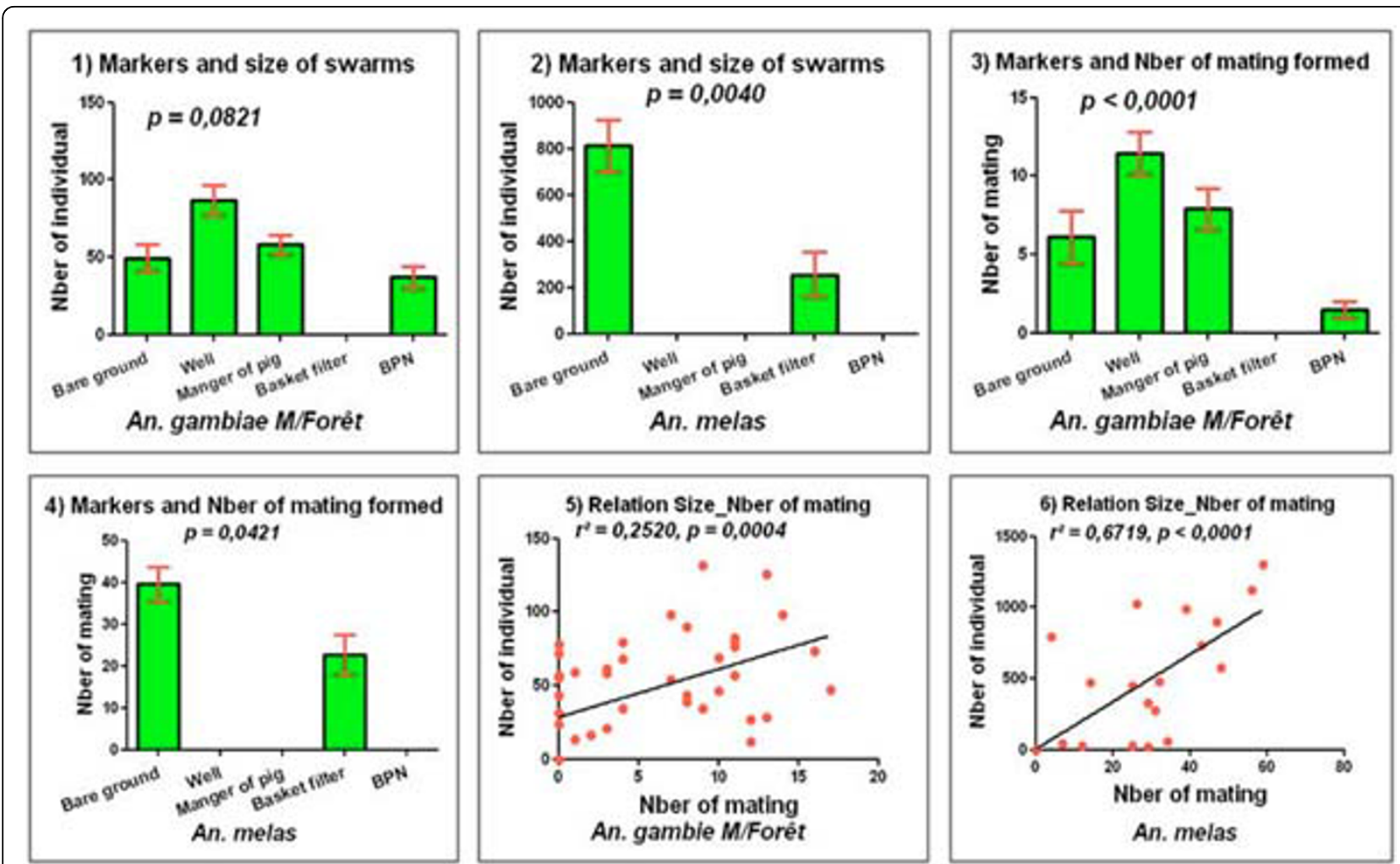

Figure 3 Relation between swarming markers and size and mating of swarms of An. gambiae s.
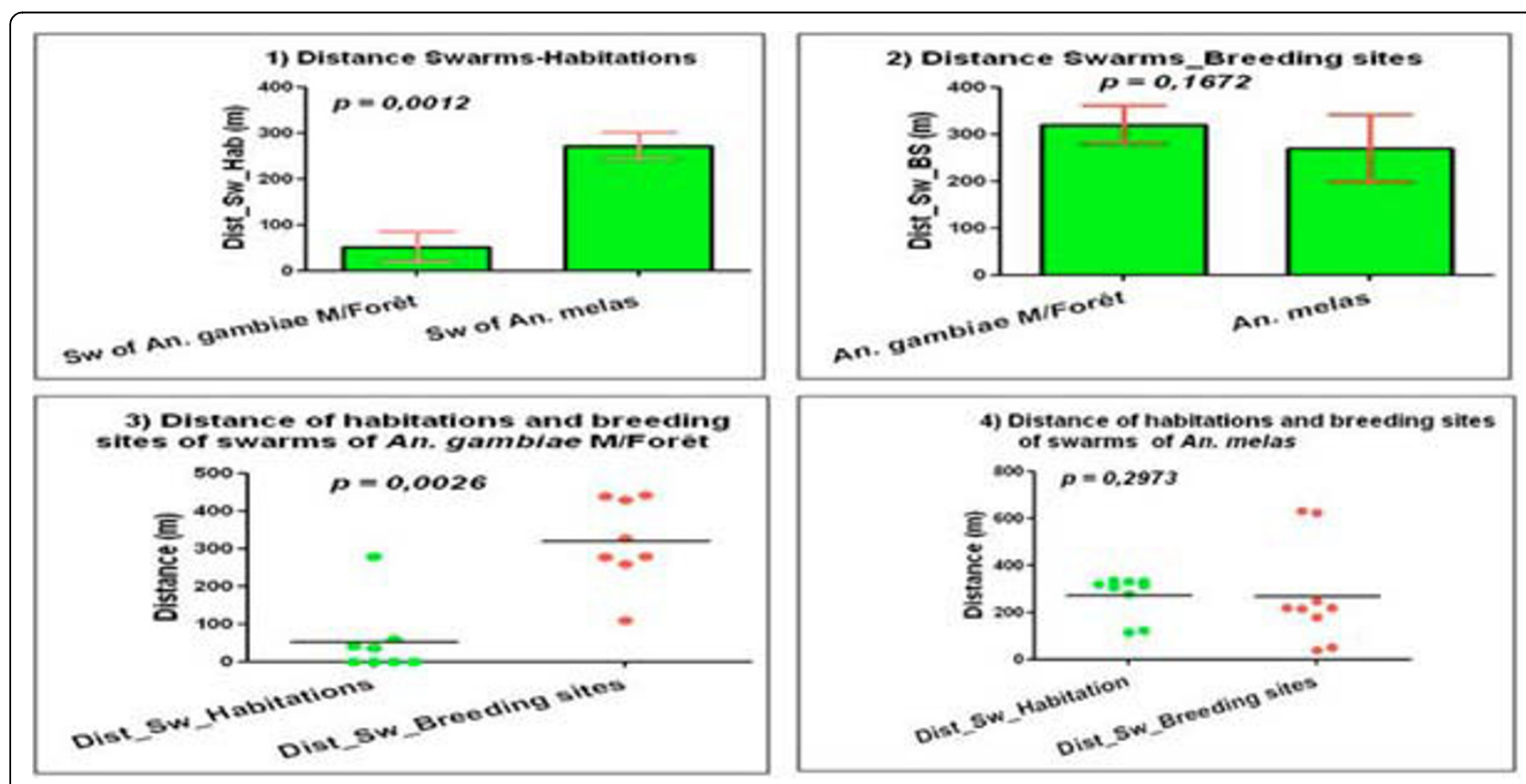

Figure 4 Relation between swarms, mosquito breeding sites and human house distribution in the study site. 


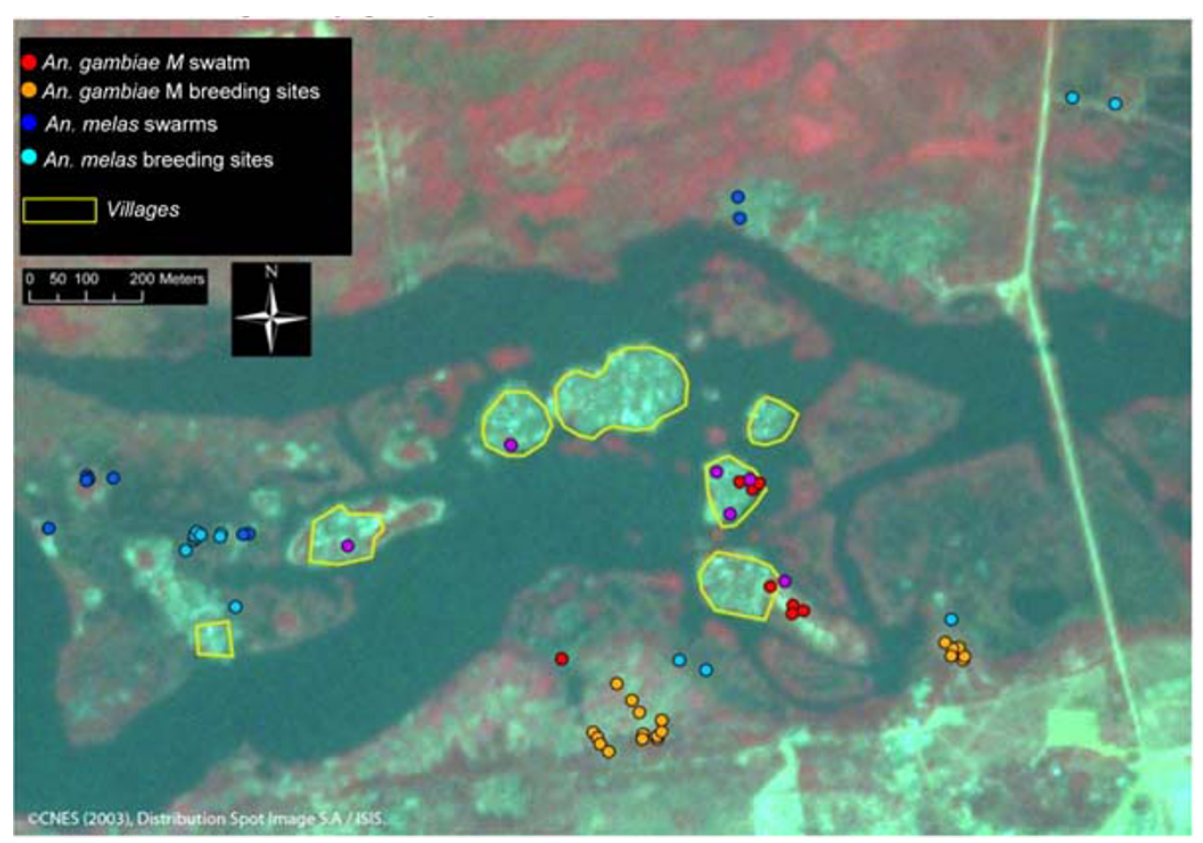

Figure 5 Distribution map of swarms and mosquito breeding sites of An. gambiae s.s. M and An. melas in the village of Djègbadji. 